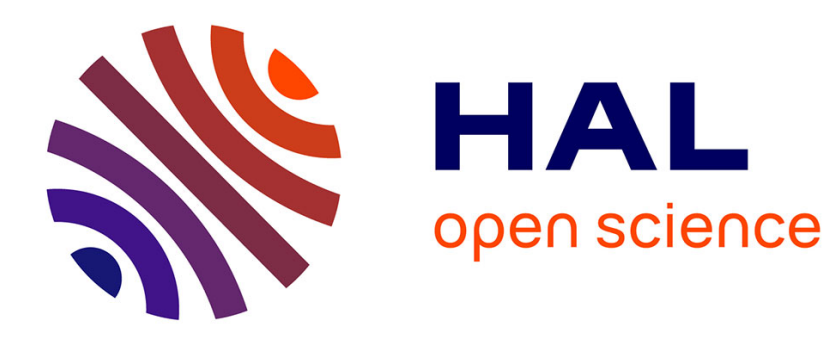

\title{
Superconductivity in doped semiconductors
}

E. Bustarret

\section{- To cite this version:}

E. Bustarret. Superconductivity in doped semiconductors. Physica C: Superconductivity and its Applications, 2015, 514, pp.36. 10.1016/j.physc.2015.02.021 . hal-01218912

\section{HAL Id: hal-01218912 \\ https://hal.science/hal-01218912}

Submitted on 21 Oct 2015

HAL is a multi-disciplinary open access archive for the deposit and dissemination of scientific research documents, whether they are published or not. The documents may come from teaching and research institutions in France or abroad, or from public or private research centers.
L'archive ouverte pluridisciplinaire HAL, est destinée au dépôt et à la diffusion de documents scientifiques de niveau recherche, publiés ou non, émanant des établissements d'enseignement et de recherche français ou étrangers, des laboratoires publics ou privés. 
To be published in a Special Issue of Physica C, vol. 514, page 36 (2015)

\title{
Superconductivity in doped semiconductors
}

\author{
E. Bustarret ${ }^{a, b}$
}

a) CNRS, Inst. NEEL, 25 rue des Martyrs, 38042 Grenoble, France

b) University of Grenoble Alpes, Inst. NEEL, 38042 Grenoble, France

Etienne.bustarret@neel.cnrs.fr $\quad+33476887468$

A historical survey of the main normal and superconducting state properties of several semiconductors doped into superconductivity is proposed. This class of materials includes selenides, tellurides, oxides and column-IV semiconductors. Most of the experimental data point to a weak coupling pairing mechanism, probably phonon-mediated in the case of diamond, but probably not in the case of strontium titanate, these being the most intensively studied materials over the last decade. Despite promising theoretical predictions based on a conventional mechanism, the occurrence of critical temperatures significantly higher than $10 \mathrm{~K}$ has not been yet verified. However, the class provides an enticing playground for testing theories and devices alike.

Introduction : half a century in a nutshell.

The notion that "doping" an insulating material by inserting or substituting atoms with a different valence state may bring about superconductivity (below an experimentally accessible critical temperature $T_{c}$ ) is not new. It has been successfully applied to various classes of solids, whereby the resulting free carrier density became a tunable variable, as illustrated in many contributions to this special issue. However, there was a time when the occurrence of superconductivity in materials with appreciably less than one carrier per atom was an open question. The main reason for this was that a lower carrier density was expected to reduce the efficiency of dielectric screening to the point where Coulomb repulsion could not be overcome by any pairing mechanism. In this context, the idea that semiconductors chemically doped beyond the critical value $\mathrm{n}_{\text {MIT }}$ for a metal-insulator transition to occur would eventually become superconductors was suggested and discussed quite early on for three-dimensional (3d) degenerate systems $\mathrm{s}^{1-4}$. It was experimentally applied in the 60's to self-doped (with holes) narrow bandgap semiconductors, mostly tellurides such as GeTe ${ }^{5,6}$, SnTe ${ }^{7-9}$, and the at that time more controversial $\mathrm{PbTe}^{10,11}$. Electron doped systems were also investigated such as $\mathrm{La}_{3-}$ ${ }_{y} \mathrm{Se}_{4}{ }^{12,13}$ and other lanthanum compounds, or the more popular reduced (or Nb-doped) $\mathrm{SrTiO}_{3}{ }^{14,15}$, a much wider bandgap semiconductor. In the case of GeTe, the "gap ratio" of the superconducting gap width $2 \Delta$ ( $\Delta$ being the binding energy of the Cooper pair) to its critical thermal energy $k_{B} T_{C}$ was 
measured $^{16}$. The value of 4.3 was taken at the time as a confirmation of the conventional weak coupling mechanism usually referred to as ${ }^{17} \mathrm{BCS}$, which predicted a gap ratio of 3.5. Probably because increasing the carrier concentration $n_{e}$ in these systems did not enhance the $T_{c}$ values above $500 \mathrm{mK}$ (the $T_{C}$ vs $n_{e}$ curve even followed a "dome" shape in one case ${ }^{15}$, or because the observations remained restricted to "ionic" semiconductors, this initial interest did not last ${ }^{16,17}$.

One generation later, the observation of superconductivity $\left(T_{C}=8 \mathrm{~K}\right)$ in silicon clathrates where alkaline earth metals had been inserted in the cages for doping showed that $\mathrm{sp}^{3}$ hybridization of column IV elements was compatible with superconductivity ${ }^{19,20}$. Such experiments were inspired by studies of superconducting alkali-doped fullerenes (see the article by A. Ramirez in this issue). Their quantitative modelling ${ }^{21}$ by ab initio calculations and a conventional pairing mechanism illustrated the strength of the electron-phonon coupling in rigid $\mathrm{sp}^{3}$-bonded networks, and pointed to carbonbased clathrates as a route toward a higher $\mathrm{T}_{\mathrm{c}}$. Although quite telling in hindsight, these findings were not the origin of the discovery published the following year ${ }^{22}$ of type II superconductivity $\left(T_{C}=2.6 \mathrm{~K}\right.$, onset at $\left.4 \mathrm{~K}\right)$ in polycrystalline boron-doped diamond grown at high pressure and high temperature (HPHT). This seminal report, which included magnetotransport and magnetic susceptibility measurements, was quickly confirmed by other groups for boron-doped polycrystalline ${ }^{23}$ and homoepitaxia ${ }^{24}$ diamond films grown by Microwave Plasma-enhanced Chemical Vapor Deposition (MPCVD). As reviewed a few years ago ${ }^{25,26}$, many groups have reproduced and extended these initial results, with transition onset temperatures soon reaching the $10 \mathrm{~K}$ mark in polycrystalline thick films. As for single crystal diamond, the maximum $T_{C}$ reported so far was $8 \mathrm{~K}$ in $\mathrm{C}: \mathrm{B}$ epilayers ${ }^{27}$ grown along (111), written as $\mathrm{C}_{(111)}$ :B in the following.

Such experimental evidence for superconductivity in boron-doped diamond motivated many theoretical quantitative studies. In order to estimate the maximum critical temperature that could be explained under the assumption of a phonon-assisted pairing mechanism, most of these resorted to numerical calculations involving the Virtual Crystal Approximation ${ }^{28,29}$ (VCA), periodic supercells ${ }^{30,31}$, or both ${ }^{32}$. In some cases, the random incorporation of boron was taken into account ${ }^{33-35}$ by using the Coherent Potential Approximation (CPA). These studies generally used the calculated electronic and vibronic band structure to derive the electron-phonon coupling spectral distribution (the so-called Eliashberg function $\alpha^{2} F(\omega)$ ) and to compute the average coupling strength parameter $\lambda$ by integrating the $U \mathrm{~g}_{\mathrm{F}}$ product over the Fermi surface, $\mathrm{g}_{\mathrm{F}}$ being the density of electronic states at the Fermi level $E_{F}$ (defining a Fermi temperature $T_{F}$ ) and $U$ the electron-phonon interaction potential. In diamond, because of the stiff $3 \mathrm{~d}$ network resulting from $\mathrm{sp}^{3}$ hybridization of the carbon atoms, $U$ was found to be stronger than in the parent $\mathrm{MgB}_{2}$ covalent superconductor ${ }^{36}$, but $\mathrm{g}_{\mathrm{F}}$ was much lower, leading to calculated $\lambda$ values lying between 0.15 and 0.55 depending on the calculation method, for a doping level in the few at.\% range. This was significantly lower than in $\mathrm{MgB}_{2}$, where $\lambda$ is close to 1 . These theoretical works then used the McMillan formula ${ }^{37}$ to estimate $T_{c}$ as a function of $\lambda$, of a logarithmic average phonon frequency represented here by the Debye energy $k_{B} \theta_{D}$, and of the screened and retarded Coulomb repulsion potential $\mu$ usually expressed as $\mu^{*}=\mu /\left[1+\mu \log \left(T_{F} / \theta_{D}\right)\right]$. With these parameters, this formula reads:

$\mathrm{T}_{\mathrm{C}}=\theta_{\mathrm{D}} / 1.45 \exp \left[-(1.04(1+\lambda)) /\left(\lambda-\mu^{*}(1+0.62 \lambda)\right)\right]$

Eqn. 1

In diamond, $\theta_{D}=2000 \mathrm{~K}$, quite a high value. As for $\mu^{*}$, most of the authors assumed that the values typical for metals $\left(\mu^{*}=0.15\right.$ ) still applied, despite the fact that the Fermi energy $E_{F}$ and the average 
phonon energy described by $k_{B} \theta_{D}$ were comparable in superconducting diamond (see table 1 ). Such an approach reproduced most of the trends of the experimental results, such as the magnitude of $T_{C}$ or the negative sign of the pressure coefficient ${ }^{38}$, and provided some insight as to which phonons contributed most significantly to the coupling ${ }^{30-32}$. However, the simulations failed to reproduce the values of $T_{c}$ when the free hole concentration $n_{h}$ was reduced down to $n_{\text {MIT }}$, as well as the curvature of the experimental $T_{C}$ vs $n_{h}$ variations ${ }^{34,35,39,40}$. Rescaling the coupling and screening parameters $\lambda$ and $\mu^{*}$ according to power laws close to the critical concentration has been proposed for diamond ${ }^{40}$ and silicon ${ }^{41}$ but remains specific and unsatisfactory. More general descriptions ${ }^{42,43}$ of the effect of approaching the MIT in disordered metals yield $T_{C}$ enhancements which have not been detected in the materials under study here. Unfortunately, the powerful parameter-free approach where the Coulomb pseudo-potential $\mu$ does not need to be adjusted ${ }^{44}$ has not been applied to any of the superconducting semiconductors so far. This situation prompted alternative theoretical approaches either based on the resonating valence bond model which assumes transport within an impurity band ${ }^{45}$, at the crossover between the host band and the impurity band ${ }^{46}$, or which relied on attractive spin-spin interactions between weakly localized holes near the Fermi level ${ }^{47,48}$. Meanwhile, under the assumption of optical phonon-mediated pairing, the maximum achievable $T_{c}$ in diamond has been tentatively estimated ${ }^{49,50}$. In a similar manner, it was predicted ${ }^{51,52}$ that the rhombohedral $\mathrm{B}_{13} \mathrm{C}_{2}$ and cubic $\mathrm{BC}_{5}$ compounds would yield a $\mathrm{T}_{\mathrm{C}}$ value close to that observed in $\mathrm{MgB}_{2}$.

The calculated transition temperatures of a few $\mathrm{K}$ as detailed above for hole-doped diamond were also considered by some authors ${ }^{28,53}$ to be in sufficient agreement with experiment to warrant predictions of p-type superconductivity in other column IV semiconducting materials, namely $\mathrm{Si}$ and Ge. Despite the notorious incapacity of BCS theory to predict new superconductors ${ }^{54}$, experimental evidence for superconductivity was gathered over the next few years, first in silicon ${ }^{55}$, then in silicon carbide ${ }^{56}$, both upon boron doping in the few at. \% range, with $\mathrm{T}_{\mathrm{C}}$ soon ${ }^{57}$ reaching $1.5 \mathrm{~K}$ in $3 \mathrm{C}-\mathrm{SiC}: \mathrm{B}$ and $6 \mathrm{H}-\mathrm{SiC}: \mathrm{B}$ (cubic $3 \mathrm{C}$ and hexagonal $6 \mathrm{H}$ are two of the many polytypes of silicon carbide), and more recently ${ }^{41} 0.7 \mathrm{~K}$ in Si:B. Ab initio calculations in the spirit detailed above were performed about superconductive $\mathrm{Si}: \mathrm{B}$, resulting in $\lambda$ values which remained ${ }^{41,55}$ below 0.45 even for 10 at.\% $\mathrm{B}$. Other dopants of silicon have also been investigated ${ }^{58}$, the calculations pointing out the detrimental influence on the electron-phonon coupling strength of the lattice contraction brought about by atomic substitution by impurities with a smaller covalent radius, so that substitutional doping ( $\mathrm{n}$ type) of silicon with aluminum was seen theoretically as a favorable (but notoriously unpractical) option. Similar calculations have been proposed ${ }^{59,60}$ also in the case of SiC:B, where less energetic acoustic phonons were shown to come into play, in good agreement with specific heat measurements ${ }^{61}$. Further experimental studies showed that (p-type) doping 3C-SiC with aluminum $^{62,63}$ yielded a similar $T_{c}$ of $1.45 \mathrm{~K}$.

The next column IV indirect bandgap semiconductor to be doped into superconductivity (see ref. 64 for a review) was germanium ${ }^{65}$, with a maximum $T_{c}$ of $0.5 \mathrm{~K}$ in Ge:Ga, again in rough agreement with $a b$ initio calculations ${ }^{66}$. Further optimization ${ }^{67}$ of the flash annealing conditions led to an increase of $T_{C}$ from about 0.2 to $0.5 \mathrm{~K}$ as the Hall carrier density $\mathrm{n}_{H}$ was varied from 2 to $5 \times 10^{20} \mathrm{~cm}^{-3}$. Other annealing strategies yielded less systematic variations, among which a few higher $T_{c}$ values, at $1.2 \mathrm{~K}$ for ${ }^{68} \mathrm{n}_{\mathrm{H}}=11 \times 10^{20} \mathrm{~cm}^{-3}$, and $1 \mathrm{~K}$ for ${ }^{69} \mathrm{n}_{\mathrm{H}}=6 \times 10^{20} \mathrm{~cm}^{-3}$. In parallel, a similar experimental process was applied by the same group on silicon, and $\mathrm{SiO}_{2}: \mathrm{Ga} / \mathrm{Si}: \mathrm{Ga}$ composites were shown to be superconducting ${ }^{70}$. However, Aluminum and Gallium being superconducting elementary metals with respective $T_{C}$ of $1.2 \mathrm{~K}$ and $1.1 \mathrm{~K}$, the authors have considered the possibility that the 
superconductivity originated from Al or Ga clusters. They have so far concluded that Ga-rich amorphous nano-inclusions are present only in the case ${ }^{71}$ of Si:Ga. As explained in a recent summarizing overview ${ }^{72}$, such caveats apply to any compound containing one element (for instance $\mathrm{Pb}$, In or $\mathrm{Ga}$ ) which may form a superconducting island. This is the reason why except for the specific case of $\mathrm{PbTe}^{73}$, the numerous reports about PbSe, $\operatorname{lnN}$ and $\ln _{2} \mathrm{O}_{3}$, or $\mathrm{GaAs}$ and $\mathrm{GaN}$, despite their quality, will not be mentioned in this review. We shall also discard from the present survey the numerous and in general disordered metallic compounds containing $\mathrm{Si}$ or $\mathrm{Ge}$, either binary (for example $\mathrm{Au}: \mathrm{Si}, \mathrm{Mo}: \mathrm{Si}, \mathrm{W}: \mathrm{Si}, \mathrm{CoSi}_{2}, \mathrm{Cu}: \mathrm{Ge}$ ) or ternary, despite their interesting low temperature transport properties, including superconductivity. Doped cubic silicon clathrates and non-cubic high pressure superconducting phases of silicon will also be ignored, as well as the numerous superconducting carbon allotropes (such as metal-intercalated graphites and fullerites), most of which are described elsewhere in this special issue.

As a matter of fact, a high pressure phase of solid boron is also superconducting, but its presence has been consistently ruled out in the boron-doped semiconductors under consideration here. The aggregation of boron has been the object of some attention in the case of diamond, where boron pairing has been found energetically favorable ${ }^{74}$ in heavily-doped crystals. Aggregation in boron-rich regions has been observed in grain boundaries ${ }^{75,76}$, without any clear correlation with superconductivity ${ }^{77}$. On the contrary, in cases where the grain boundaries became atomically thin, the boron-rich triple points (most probably $\mathrm{B}_{4} \mathrm{C}$ ) were found to remain in the normal state ${ }^{78}$ at low temperatures. The formation of $\mathrm{B}_{4} \mathrm{C}$ crystalline particles on the (111) surface of diamond single crystals doped during their HPHT growth by the temperature gradient method has also been reported recently ${ }^{79}$. Anyway, the quest for the boron-rich superconducting phases predicted theoretically ${ }^{51,52,80}$ has not been successful so $\mathrm{far}^{81}$. Although the spatial distribution of boron atoms has been recognized as a source of short range disorder, and of grain-to-grain heterogeneity in polycrystalline diamond ${ }^{77,82}$, no such clustering has yet been reported to take place in single crystal $\mathrm{C}: \mathrm{B}$, nor in Si:B epilayers ${ }^{83}$. Actually, from a material synthesis point of view, it must be stressed that most of the advances just described result from the recently available possibility of circumventing the solubility limit of the dopant impurities in the host material by using out-of equilibrium processing techniques such as Gas Laser Immersion laser doping ${ }^{84}$ or shallow implantation/flash annealing sequences ${ }^{85,86}$.

Coming back to some of the superconducting semiconductors which were studied most intensively half a century ago, one cannot fail to mention that single crystal SnTe is nowadays considered as a crystalline topological insulator ${ }^{87,88}$ when it is low-doped and in the rocksalt structure (its low T phase). Moreover, In-doped SnTe is an intriguing superconductor in its own right ${ }^{11,89}$, as are Tldoped $^{73,90,91} \mathrm{PbTe}$ and even more so In-doped PbTe, which features both ferroelectricity at low In content (rhomboedral phase) and ${ }^{92}$ "topological superconductivity" above a critical In content of a few at.\%, at which a structural transition to a cubic rocksalt phase occurs. Such aspects are dealt with in S. Sasaki's contribution in this volume. In the case of $\mathrm{La}_{3-y} \mathrm{Se}_{4}$, it is the thermoelectric properties that are drawing increasing interest ${ }^{93}$. As for $\mathrm{SrTiO}_{3}$, it is still the most dilute $3 \mathrm{~d}$ superconductor by $\mathrm{far}^{94}$, down to free electron density values around $510^{17} \mathrm{~cm}^{-3}$ which challenge any BCS-type of pairing mechanism ${ }^{95}$. It has been the object of many studies spread over the last 50 years ${ }^{96}$. Recently, it has been shown (see the contribution of Triscone \& Gabay in this special issue) that the interface of $\mathrm{SrTiO}_{3}$ with another oxide could give rise to a $2 \mathrm{~d}$ metal with a superconducting ground state ${ }^{97,98}$. Before describing in the next sections the normal and superconducting $3 \mathrm{~d}$ states of some of the 
materials mentioned in this introductory historical overview, we propose to summarize in fig. 1 their $T_{c}$ dependence on the nominal free charge carrier density as estimated from Hall effect, (except in the case of silicon, where boron concentrations have been used) in the spirit of a previous and broader review ${ }^{99}$. Beside the usual uncertainties on the critical temperature values arising from an author's dependent definition, it should be stressed that the direct derivation of the apparent normal state carrier density from Hall effect data suffers from shortcomings related either to macroscopic doping heterogeneities or to the Fermi surface shape-dependent value of the Hall factor, which may differ significantly from unity. As a matter of fact, such apparent densities have been found to be larger than the chemical concentration of the doping element by $50 \% \mathrm{in}^{9} \mathrm{SnTe}$, and by up to an order of magnitude in diamond ${ }^{27,40}$. A numerical application of equation 1 to the case of silicon $\left(\theta_{D}=640 \mathrm{~K}\right)$ using a boron concentration-dependent electron-phonon coupling parameter $\lambda$ evaluated by ab initio supercell calculations ${ }^{41}$ is also given in fig. 1 to illustrate the shortcomings of such a simple approach when it comes to predicting $T_{C}$ variations over a wide range of concentrations. Figure 1 also displays some scatter among the experimental data coming from different groups. In the particular case of silicon, $T_{c}$ depends on thickness (hence the two sets of points in fig. 1 ) in such a way that it seems to be determined by the sheet boron density rather than by its volumic concentration ${ }^{41}$.

\section{3d normal state properties}

Many of the standard properties of the above-mentioned materials can be found in current handbooks and databases, albeit referring mostly to their undoped semiconducting state. Some low $T$ but normal state parameters usually deemed ${ }^{11}$ to be relevant for the discussion of the superconductivity are listed in table 1 for the three tin and germanium and lead tellurides ${ }^{91,100,101}$, strontium titanate ${ }^{94}$, as well as for the four group IV covalent superconductors: germanium ${ }^{67}$, silicon $^{41}$, silicon carbide ${ }^{57,62}$ and diamond ${ }^{27}$. The cubic fcc structure of germanium telluride at high temperature becomes rhombohedrally distorted along the cube diagonal at room temperature and below. Strontium titanate has a cubic perovskite crystal structure at room temperature and undergoes a structural transition to tetragonal around $110 \mathrm{~K}$ or lower, depending on the self-doping level. All other materials have a cubic structure, except for the 6C-SiC polytype. The bandgap width $E_{G}$ as well as the Debye temperature $\theta_{D}$ and the relative permittivity at low frequency $\varepsilon_{r}$ are expected to vary upon heavy doping: for example, on the basis of specific heat measurements of superconducting samples, $\theta_{\mathrm{D}}$ in $3 \mathrm{C}$-SiC:B has been estimated ${ }^{61}$ at $590 \mathrm{~K}$ and that of heavily doped bulk diamond ${ }^{102} \mathrm{C}: \mathrm{B}$ at $1440 \mathrm{~K}$, i.e. much lower than the nominal values given in table 1 . It should be mentioned however that in other HPHT C:B samples, similar measurements indicated that $\theta_{D}$ remained unaffected ${ }^{103}$. As for the Bohr radius of the acceptor or donor impurity, it is given by $r_{\text {Bohr }}=$ $\varepsilon_{r} \hbar^{2} / m^{*}{ }_{\text {Bohr }} e^{2}$ within the hydrogenoid approximation parametrized by a specific effective mass $\mathrm{m}^{*}{ }_{\text {Bohr }}$. This radius provides ${ }^{104,105}$ an estimate for the critical impurity concentration $\mathrm{n}_{\text {MIT }}$ at the metalinsulator transition (MIT) according to Mott's prediction $\mathrm{r}_{\mathrm{Bohr}} \mathrm{n}_{\mathrm{MIT}}{ }^{1 / 3}=0.26$. This critical concentration has not been determined experimentally in all systems considered here, but is known to vary over a wide range, from below $10^{16} \mathrm{~cm}^{-3}$ in $\mathrm{SrTiO}_{3}$ (a material possibly deviating from Mott's prediction) to 4 $10^{17}$ in Ge and $4 \times 10^{18} \mathrm{in}^{106} \mathrm{Si}: \mathrm{B}$ and $3-5 \times 10^{20} \mathrm{~cm}^{-3} \mathrm{in}^{27,40} \mathrm{C}_{(111):} \mathrm{B}$ and $\mathrm{C}_{(100)}$ : $\mathrm{B}$. The critical exponents around this $3 \mathrm{~d}$ MIT have been determined in the latter two materials ${ }^{40,106}$. Superconductivity was experimentally observed in these materials above a concentration $n_{c}$ min which was equal to or greater than $\mathrm{n}_{\text {MIT. }}$. The corresponding range of Fermi energies was estimated in table 1 by the 
minimum Fermi temperature $T_{F}$ min calculated within a one band free electron picture $\left(m^{*}=1\right)$. Its ratio to the Debye temperature is larger than 10 in the tellurides, but decreases when increasing the bandgap from 4 in germanium to about one in diamond, where the applicability of the adiabatic approximation and of the usual $\mu^{*}$ value might be questioned. As for $\mathrm{SrTiO}_{3}$, it yields a much smaller ratio, on the order of 0.1 , comparable to the situation of heavy-fermion superconductors, making a phonon-mediated pairing mechanism very unlikely ${ }^{94}$ and calling for alternative models ${ }^{107}$.

In addition, table 2 gathers some published examples ${ }^{11,39,41,55,62,67,73,91,94,95,101,108,109}$ of low temperature normal state transport parameters (Fermi vector $\mathrm{k}_{\mathrm{F}}$, low $\mathrm{T}$ conductivity, residual resistivity ratio RRR, mean free path $L_{m f p}$ and loffe-Regel parameter) which depend on the doping level of these materials, in the relevant range of apparent free carrier concentrations $\mathrm{n}_{H}$ deduced from the Hall coefficient. The Fermi vector $\mathrm{k}_{\mathrm{F}}$ was deduced from Shubnikov-de Haas oscillations (SnTe) or Nernst effect $\left(\mathrm{SrTiO}_{3}\right)$ measurements when available, and from free electron estimates for $\mathrm{Ge}, \mathrm{Si}, \mathrm{SiC}$ and diamond. Moreover, effective density of states relative masses $m^{*}$ dos of 2, 2.4 and 5 respectively in ${ }^{11,18} \mathrm{SnTe}$, in GeTe and $\mathrm{in}^{110} \mathrm{SrTiO}_{3}$ have been deduced from the Sommerfeld coefficient determined by specific heat measurements. More recently, similar studies yielded mass values of 1.2 and 1.7 in the cases of $^{61} \mathrm{SiC}: \mathrm{B}$ and $^{102} \mathrm{C}: \mathrm{B}$. Angle-resolved photoemission spectroscopy (ARPES) measurements of superconducting diamond epilayers have shown that their electronic band structure could not be distinguished from that of epilayers doped below the critical concentration $n_{c} m i n$, and that both were the same as that of the undoped crystal ${ }^{111}$. They yielded a few $2 \mathrm{~d}$ projections of the Fermi surface for epilayers grown along ${ }^{111,112}(111)$ and $^{113}(100)$. As illustrated by fig. 2 , in the latter case, under a polarized incident synchrotron beam, rotating the sample surface by $45^{\circ}$ led to two partial projections on the $\Gamma-X-K$ plane of the Brillouin zone corresponding respectively to the light and heavy hole subbands. Assuming that the boron concentration provides an estimate of the hole concentration $n_{h}$ at the surface of this sample led to $k_{F}=3.3 n^{-1}$, in rough agreement with the green contours shown in fig. 2, despite the fact that the heavy hole subbands do not lead to a spherical Fermi surface ${ }^{53}$, a feature that might explain the Hall factor deviating from unity ${ }^{27}$. Please note that in all experiments, the photoemission of unreconstructed heavily doped diamond surfaces could be analyzed as representative of the bulk of the crystal. Finally, since most free carrier concentrations given in tables 1 and 2 correspond to a plasmon frequency $\omega_{p}$ lying in the near or mid-infrared range, optical spectroscopies have also been applied to SnTe and ${ }^{100} \mathrm{GeTe}$, as well as to heavily doped silicon $^{114}$ and diamond ${ }^{115-117}$. A simple interpretation of the plasmon edge within the Drude model has been found sufficient in most cases to yield carrier concentrations and damping factors $\gamma=\tau^{-1}$ typical of overdamped dilute metals, with relaxation times $\tau$ in the 0.2 to $10 \mathrm{fs}$ range fully compatible with the mean free path values given in table 2, generally lower than $1 \mathrm{~nm}$ in diamond, as confirmed by ARPES measurements ${ }^{111}$.

In principle, a quantitative Kramers-Kronig analysis of the optical spectral response in the infrared energy range of lattice phonon or impurity-related vibrational modes should yield the Eliashberg function $\alpha^{2} F(\omega)$ describing the spectral variation of the electron phonon coupling parameter. In practice, this challenge has been taken up in the case of diamond ${ }^{116}$, whereby the dominant contribution of optical phonons and the possible contribution of boron-related local modes predicted by ab initio numerical studies ${ }^{30-32}$ were confirmed. The electron-phonon coupling was also illustrated by high resolution studies of photoemission phonon replicas of the Fermi edge in superconducting diamond ${ }^{118}$. Since the phonons involved in the coupling are expected to be softened, Raman studies 
have been performed on superconducting silicon ${ }^{55}$ and diamond ${ }^{119}$ and zone-center optical phonon frequencies have been extracted from first order Raman spectra, despite their polarization- and excitation energy- dependent Fano lineshape deformation ${ }^{120}$. The resulting softening values, $3 \%$ at most $^{55,119}$, were significantly weaker than predicted by VCA calculations ${ }^{28,29}$. Before being used for estimating the electron-phonon coupling strength for these particular phonons, they should moreover be corrected for doping-induced lattice strain ${ }^{119}$ which affects mostly the lattice parameter along the growth direction in the case of unrelaxed homepitaxial layers $27,55,120,121$. More to the point, second order Raman ${ }^{123}$ or inelastic X-ray ${ }^{124,125}$ scattering (IXS) allowed to detect lattice phonons away from the zone center and have confirmed that in the case of diamond the optical phonons were specifically affected in the region of the Brillouin zone occupied by free holes, as illustrated in fig. 2 . However, even in that case, the softening (up to $5 \%$ ) was much weaker than predicted ${ }^{124}$, while the broadening of the IXS phonon lines could not be explained without invoking additional disorder effects or even macroscopic heterogeneities in these very thick epilayers. Average coupling parameter $\lambda$ values deduced from such measurements ranged from 0.2 to 0.4 depending on the derivation method ${ }^{36}$, still too low for equation 1 to account for the $T_{C}$ values measured on the same samples.

Another striking feature common to many of the materials listed in table 2 is the low value of the residual resistivity ratio $\mathrm{RRR}=\sigma_{4 k} / \sigma_{300 k}$, around unity in $\mathrm{GeTe}, \mathrm{Ge}, \mathrm{Si}$, and diamond. This stems from two opposite and slow variations of the normal state resistivity above and below a specific temperature at which the inelastic mean free path becomes of the order of the elastic scattering length, resulting in a broad and weak resistivity minimum. This temperature lies around $40 \mathrm{~K} \mathrm{in}{ }^{55} \mathrm{Si}: \mathrm{B}$, above $^{25} 150 \mathrm{~K}$ and up to ${ }^{22,39} 300 \mathrm{~K}$ in C:B. Below that temperature, the resistivity increases when the temperature decreases and goes through a peak before dropping sharply at the superconducting transition temperature $T_{c}$. In the range between $T_{c}$ and about $40 \mathrm{~K}$, the conductivity extrapolates to a finite temperature according to the weak localization expression ${ }^{25,109,126}: \sigma(T)=\sigma_{0}+A_{e e} T^{1 / 2}+B_{e p} T$, where $A_{e e}$ and $B$ ep refer respectively to interelectronic and electron-phonon interactions. As described below, the resistivity peak at low $\mathrm{T}$ is significantly enhanced in heavily doped nanocrystalline ( $\mathrm{nc}-\mathrm{C}: \mathrm{B}$ ) diamond films $\mathrm{s}^{127-129}$ while the magnetoresistance changed $\operatorname{sign}^{128,130}$ with the field, as expected for a granular system. The weak localization observed in the granular disordered metal nc-C:B has been proposed to herald an unconventional superconductivity in that material through a spin-flip pairing mechanism ${ }^{127,131}$. Although presenting also a dip at intermediate temperature ${ }^{91}$, the variations of the resistivity of $\mathrm{PbTe}: \mathrm{Tl}$ have been ascribed to a charge Kondo effect ${ }^{73,91}$, i.e. a totally different effect which has important consequences for the interpretation of the superconductivity in this compound ${ }^{132}$. The last item listed in table 2 is the loffe-Regel parameter $\mathrm{k}_{\mathrm{F}} \mathrm{L}_{\text {mfp }}$ : below unity, localization sets in, and the quasi-classical approximation is no longer appropriate. From the data of table 2, this has been observed so far only in diamond doped slightly above $\mathrm{n}_{\text {MIT }}$ and grown ${ }^{39,40}$ along (100).

\section{$3 d$ superconducting properties}

As outlined in the historical survey opening this review, the bulk nature of the superconducting transition in these materials has been attested by measuring the heat capacity anomaly associated to carrier pairing below $\mathrm{T}_{\mathrm{c}} \mathrm{in}^{11} \mathrm{SnTe}$, in ${ }^{6} \mathrm{GeTe}$ and ${ }^{91} \mathrm{PbTe}$, as well as $\mathrm{in}^{109} \mathrm{SrTiO}_{3}$, in ${ }^{61} \mathrm{SiC}$ and ${ }^{102}$ diamond, 
but not in germanium nor in silicon, while susceptibility data is lacking only in the case of germanium. However, the specific heat jump value was often significantly lower than expected from weak coupling BCS theory. In complement to the results mentioned in the introduction and to the $T_{C}\left(n_{H}\right)$ data plotted in fig. 1, we illustrate also in table 3 with a few examples the experimentally determined dependence on the nominal carrier concentration $n_{H}$ of various additional parameters of the superconducting state of some semiconductors, such as the critical magnetic fields $H_{c}$ or $H_{C 2}(T=0)$ depending on the superconductor type, the coherence lengths $\xi_{G L}$ and $\xi_{0}$ deduced from $H(T)$ phase diagrams through $\xi_{G L}{ }^{2}=\Phi_{0} / 2 \pi \mathrm{H}_{\mathrm{C}_{2}}(0)=\xi_{0} L_{m f p}$, the London penetration depth $\lambda_{\mathrm{L}}$ and the Ginzburg Landau parameter $\kappa_{G L}=\lambda_{L} / \xi_{G L}$. Whenever possible, the examples have been taken from the same references as those collected in table 2 . According to these values, the only system clearly ${ }^{94}$ in the clean limit was $\mathrm{SrTiO}_{3}$, while the only apparent type I superconductors were 3C-SiC:B and 6H-SiC:B. The fact that most of the materials under consideration are type II superconductors in the dirty limit fulfills early predictions ${ }^{3}$ based on the long penetration depth and short mean free path expected for such systems.

Please note that in the case of diamond, a distinction was made between a bulk (and possibly polycrystalline) HPHT sample ${ }^{102}$, and single crystal epilayers grown by MPCVD along ${ }^{39}$ (100) or along ${ }^{116}(111)$, respectively dubbed $C_{(100)}: B$ and $C_{(111)}$ : . As illustrated both by fig. 1 and table 3 , for a given apparent carrier density $n_{H}$, the $T_{C}$ values are much higher in $C_{(111)}: B$ than in $C_{(100)}: B$. This has been tentatively attributed to a better ordering of the substitutional boron impurities ${ }^{133}$ when the diamond lattice grows along (111), to a higher substitutional to interstitial (or paired substitutional ${ }^{134}$ ) incorporation ratio for (111)-oriented growth, and finally to a favorable tetragonal strain state ${ }^{27}$ of the (111)-oriented epilayers when compared to the isotropic dislocation-rich ${ }^{135}$ relaxed state ${ }^{27}$ of the (100)-oriented epilayers grown in the same reactor. However, the opposite situation, where dislocations appear in (111)-oriented epilayers at a lower boron concentration than in layers grown along (100), has also been reported ${ }^{136}$. Anyway, a positive (tensile) strain coming from substitution by a "larger" impurity is expected to enhance $T_{C}$ in group IV superconducting semiconductors ${ }^{21,58}$, in agreement with experimental ${ }^{22,137}$ and theoretical ${ }^{38}$ results showing that in diamond the hydrostatic pressure coefficient of $\mathrm{T}_{C}$ is negative. It is also worth noting that for strained epilayers, the band splitting of the heavy and light hole bands at $\Gamma$ induced by the tetragonal strain is expected to modify the shape of the Fermi surface, and thus to affect both the Hall factor and the critical temperature. This strain has opposite signs in Si:B and C:B.

Since the pioneering tunnel spectroscopy studies ${ }^{16}$ of GeTe, the superconducting gap of energy seen by the quasiparticles around the Fermi level has been investigated $\mathrm{in}^{96,138} \mathrm{SrTiO}_{3}$, in $^{139} C_{(100)}: B$, in $^{140}$ $\mathrm{C}: \mathrm{B}, \mathrm{in}^{141,142} \mathrm{C}_{(111)}$ :B and ${ }^{143} \mathrm{Si}: \mathrm{B}$. Thanks to the development of ultra-low T scanning tunnel microscopy (STM) and spectroscopy (STS), the latter studies have provided local maps of the local variations of the coherence peak intensity and of the superconducting gap ${ }^{139,142,143}$. In the case of $C_{(100)}$ : $B$ surfaces, vortex images and some evidence for localized gap states were obtained, the latter remaining a puzzle ${ }^{63,139}$. The temperature dependence of the local pair binding energy $\Delta$ deduced from the excitation gap has been also studied in diamond and silicon, and found in excellent agreement with a $s$-wave BCS superconductivity with a BCS ratio $\Delta / \mathrm{k}_{\mathrm{B}} \mathrm{T}_{\mathrm{C}}=1.75$ both for a $\mathrm{C}: \mathrm{B}$ plate ${ }^{140}$ and $\mathrm{C}_{(100)}: \mathrm{B}$ epilayers $^{123,139}$, while a $20 \%$ dispersion about the BCS value was observed ${ }^{143}$ on Si:B. Two coupled gaps had been detected earlier in $\mathrm{SrTiO}_{3}$, with a $\mathrm{BCS}$ ratio close to 1.76 for the larger one ${ }^{96}$, as well as a possible signature of the soft phonon mode at $1.9 \mathrm{meV}$ involved in the low temperature structural 
transition ${ }^{138}$. Moreover, optical methods have yielded superconducting gap values for $C_{(111)}: B$, infrared and $\mathrm{THz}$ spectroscopies ${ }^{116}$ appearing to be better suited than high resolution photoemission ${ }^{109}$ for the purpose. The resulting $\Delta$ values were plotted in fig. 3 as a function of the critical temperature $T_{C}$, and found to be fully compatible with a conventional weak coupling $B C S$ description. Finally, a crucial test of the nature of the pairing attractive interaction is of course the isotope atomic mass (M) effect on $T_{c}$, usually quantified by the exponent $\beta=-d \log T_{c} / d \log (M) . \beta=$ 0.5 is considered the hallmark of a phonon-mediated BCS mechanism, although $\beta$ may take lower values because of Coulomb repulsion effects. Specific heat measurements ${ }^{103}$ of isotopically substituted HPHT C:B have yielded a much higher $\beta$ exponent of 1.8 , while similar studies of the resistive transition led to $\beta=1.4 \pm 0.4$ for other HPHT C:B samples ${ }^{144}$, and to isotope exponent values of $0.6,1.1$ and 1.8 in $C_{(100)}$ :B epilayers ${ }^{145}$. If the isotopic mass effect seems thus to be established in the sole case of diamond, confirming the crucial role of electron-phonon coupling in this material, its magnitude remains to be explained. Frequent Cooper pair breaking ${ }^{146}$, possibly triggered by the local nature of some of the coupling phonons ${ }^{145}$, has been considered as a plausible origin for this phenomenon $^{144}$.

Applying the BCS model in the dirty limit within a one-band free electron picture, the slope at $T_{C}$ of the $H(T)$ phase diagram (at the boundary between the vortex phase and the normal phase) may also be used to estimate the loffe-Regel parameter $\left(k_{F} L_{m f p}\right)$. The values of $-1 \mathrm{~T} / \mathrm{K}$ for diamond, $-0.2 \mathrm{~T} / \mathrm{K}$ in silicon, and -0.02 to $-0.1 \mathrm{~T} / \mathrm{K}$ in GeTe lead to loffe-Regel parameter values in good agreement with those deduced from normal state transport measurements (table 2). Such a successful consistency check between superconducting and normal state properties brings further support to a weak coupling mechanism being at work in these three materials. No such agreement was found in the other materials, the mixed state estimate of $k_{F} L_{m f p}$ being significantly smaller than the normal state estimate the case of germanium, while the opposite was true for SnTe. Another point was the relevance of the proximity of a carrier concentration-induced MIT to understand the superconducting properties of diamond close to this transition. Comparison to the parent silicon system showed that, in the latter, superconductivity was not any simpler to understand in detail ${ }^{41}$, despite the absence of any MIT in the doping range of interest.

\section{Low dimensionality issues and devices}

The fact that the critical doping level for the MIT and for the onset of superconductivity $n_{c}$ min coincide in diamond has also given some impetus to studies aiming at controlling and studying a superconductor to insulator transition (SIT) in this system. As emphasized by theoretical studies promoting either a "fermionic"145 or a "bosonic"148 model for this transition, the SIT may be investigated experimentally by changing not only the carrier concentration but also the disorder and the thickness of the epitaxial film. Thickness effects on $T_{c}$ have been observed below about $200 \mathrm{~nm}$ and down to $5 \mathrm{~nm}$, but they appear similar for both epitaxial films doped far above ${ }^{135} \mathrm{n}_{\text {MIT }}$ or much closer $^{149}$ to the MIT, so that fundamental aspects of the SIT are ruled out from their interpretation. Once normalized to the $T_{c}$ "bulk" value, the observed variations may be in both cases explained by a simple geometrical effect related to a weaker order parameter at the surface ${ }^{150-1}$, but yield a critical thickness value of $25 \mathrm{~nm}$, much longer than the Thomas Fermi screening length supposed to be relevant in that case. This open question deserves further attention, at least as long as the coincidence of $n_{c}$ min with $n_{\text {MIT }}$ is not disproved. More generally, controlled ways to change the effective disorder in these superconducting semiconductors should be sought. 
Beside film thickness reduction or disorder variations, another way to induce effective dimensionality effects at a less intrinsic level is to introduce grains and to vary their size relative to the film thickness and to other physically relevant lengths. This has been performed in boron doped nanocrystalline diamond : for grain sizes smaller than the thickness and comparable to the coherence length ${ }^{152}$, or comparable to the thickness ${ }^{81,153}$, the granularity of the system takes over and percolation effects are expected. The role of the grain boundaries and intragranular metallic transport parameters, quite obvious in the normal state ${ }^{130,154,155}$ takes another twist below $\mathrm{T}_{c}$, with an influence of the intergranular Josephson coupling, as well as that of the heterogeneity of the local superconductivity among the grains and even within the same grain, which has been assessed by scanning tunnel microscopy ${ }^{77,78}$. For micrometer-sized grains, the enhanced weak localization effects may be hidden at low temperatures by a sharp and pronounced "bosonic" resistivity peak occuring at a temperature close to the onset of superconductivity ${ }^{129}$. Such granularity-induced and percolation effects do not seem to have triggered the same interest in the other superconducting semiconductors.

Patterning of micro- or nanocrystalline superconducting diamond films into wires less than $100 \mathrm{~nm}$ wide preserved their superconducting properties ${ }^{156}$ up to $1 \mathrm{~K}$ and $1 \mathrm{~T}$. Such e-beam patterned wires and loops, including a thinner region inducing a weak link, were used to make superconducting quantum interference devices (SQUID) working at magnetic fields reaching ${ }^{157} 4 \mathrm{~T}$. Similar films grown on a sacrificial silicon oxide were also patterned into double clamped suspended beams. These micromechanical resonators were driven and read out in the superconducting state at $\mathrm{MHz}$ frequencies ${ }^{158}$. Future combinations of smaller oscillators with the SQUID should soon establish the potential of superconducting nanocrystalline diamond for dissipation-free quantum opto-mechanics. Finally, in the case of diamond, the "natural" Josephson junctions occuring at grain boundaries and the "artificial" weak junctions resulting from thinning nanocrystalline wires have found ${ }^{159}$ a single crystal counterpart in vertical SNS weak-link Josephson junctions grown epitaxially along (111). When the thickness of the normal state diamond of such structures was made much larger than the coherence length, a proximity effect could be observed. Moreover, Shapiro steps were detected under microwave irradiation ${ }^{160}$. This result illustrated recent improvements in the sharpness of the doping transitions upon epitaxial MPCVD growth ${ }^{149,161}$ at the normal-superconductor interface, and opened the way for the fabrication of hybrid systems involving either optical color centers or mechanical oscillators, or both. Be it for the above mentioned quantum-limited sensing, or for quantum data processing using more elaborate devices such as Josephson field effect transistors, the ability to grow homoepitaxial Josephson junctions should improve significantly the transparency of the normal-superconductor interfaces. Similar strategies and more audacious qubits schemes have been proposed in the case of silicon ${ }^{64,162}$, but they have not yet materialized.

As mentioned at the end of the introduction (and in the contribution by Triscone \& Gabay), low dimensionality effects quite different from the above have been demonstrated for the interface of $\mathrm{SrTiO}_{3}$ with another perovskite oxide where the $2 \mathrm{~d}$ electron gas extending a few $\mathrm{nm}$ within $\mathrm{SrTiO}_{3}$ from the interface was shown to have a superconducting ground state below ${ }^{97} 0.2 \mathrm{~K}$ or $^{98} 0.3 \mathrm{~K}$. A similar $2 \mathrm{~d}$ gas was generated at the pristine $\mathrm{SrTiO}_{3}$ single crystal surface by using the electrical double layer gate created in an organic electrolyte. When sheet carrier densities of the order of $10^{14} \mathrm{~cm}^{-2}$ were obtained in this way ${ }^{163}$, an electric-field-induced $2 \mathrm{~d}$ superconducting state appeared below 0.4 $\mathrm{K}$, a $\mathrm{T}_{\mathrm{C}}$ value comparable to the values given in fig. 1 for $\mathrm{Nb}$-doped $\mathrm{SrTiO}_{3}$. 
Finally, for the sake of completeness, it should be mentioned that very high $T_{C}$ values $(145 \mathrm{~K})$ have been reported ${ }^{164}$ for a specific type of low-dimensional silicon pyramidal sandwich nanostructures self-assembled on top of $n$-type (100)-oriented wafers, whereby ultra-narrow $p$-type silicon quantum wells were confined by heavily boron-doped superconducting delta "barriers" 165 . These amazing results, which still await an independent confirmation, have been attributed to the transport of small hole bipolarons resulting from the presence of negative- $U$ centers associated to the boron impurities ${ }^{165-167}$. More generally, it must be recognized that at this moment, and similarly to the cases of germanium and silicon carbide, superconductivity studies of boron doped silicon lack independent confirmations by other groups.

\section{Summarizing remarks}

In summary, most of the experimental data currently available about single crystal (or large grain polycrystalline) superconducting semiconductors hint at a conventional pairing mechanism, except in the case of $\mathrm{PbTe}$ and $\mathrm{SrTiO}_{3}$, the latter being the only electron-doped system in the whole family. However, quantitative agreement with simple models was not yet demonstrated over a wide doping range for any of the "conventional" systems, while additional evidence is still required to assess the status and potential of germanium and silicon carbide. Except for one very recent and preliminary report ${ }^{168}$, the occurrence of critical temperatures significantly higher than $10 \mathrm{~K}$ has not been verified, despite promising theoretical predictions for $\mathrm{sp}^{3}$ carbon clathrates ${ }^{21}$ and cubic boron-carbon compounds $^{169-170}$.

Diamond clearly stands out as the most studied and archetypical group IV superconducting semiconductor ${ }^{64}$. Ten years after its discovery, this material even shows some promise for superconducting quantum devices. In the near future, much older players with less conventional superconducting properties, $\mathrm{PbTe}$ and $\mathrm{SrTiO}_{3}$, and a younger one with an impressive technological maturity, silicon, will certainly provide additional opportunities for testing new and old theories, as well as futuristic hybrid devices.

\section{Acknowledgements}

The author thanks the colleagues he has worked with on this topic over the last ten years, especially H. Guyot and M. Hoesch who allowed him to display unpublished data in fig. 2. He also thanks Dr K. Behnia and Prof. T. Klein for a critical reading of this manuscript. 


\section{References}

1 D. Pines, Phys. Rev. 109, 280 (1958).

2 V.L. Gurevich, A.I. Larkin, Yu A. Firsov, Sov. Phys. Solid State 4, 131 (1962)

3 M.L. Cohen, Rev. Mod. Phys. 37, 240 (1964).

4 M. Kohmoto, Y. Takada, J. Phys. Soc. Jpn 59, 1541 (1990).

5 R. A. Hein, J. W. Gibson, R. Mazelsky, R. C. Miller, J. K. Hulm, Phys. Rev. Lett. 12, 320 (1964).

6 L. Finegold, Phys. Rev. Lett. 13, 233 (1964).

7 R. A. Hein, J. W. Gibson, R. S. Allgaier, B. B. Houston, Jr., R. Mazelsky, R. C. Miller, in: Low Temperature Physics, LT9, edited by J. G. Daunt et al. (Plenum Press, New York, 1965), p. 604.

8 R.A. Hein, P.H.E. Meijer, Phys. Rev. 179, 497 (1969).

9 J.K. Hulm, Phys. Rev. 169, 388 (1968).

10 B. Lalevic, Phys. Lett. 16, 206 (1965).

11 J.K. Hulm, M. Ashkin, D.W. Weis, C.K. Jones, Prog. Low Temp. Phys. 6, 205 (1970).

12 R.M. Bozorth, F. Holtzberg, S. Methfessel, Phys. Rev. Lett. 14, 952 (1965).

13 F. Holtzberg, P.E. Seiden, S. von Molnar, Phys. Rev. 168, 408 (1968).

14 J. F. Schooley, W. R. Hosler, M. L. Cohen, Phys. Rev. Lett. 12, 474 (1964).

15 J.F. Schooley, W.R. Hosler, E. Ambler, J.H. Becker, M.L. Cohen, C.S Koonce, Phys. Rev. Lett. 14, 305 (1965).

16 P.J. Stiles, L. Esaki, J.F. Schooley, Phys. Lett. 23, 206 (1966).

17 J. Bardeen, L. N. Cooper, J. R. Schrieffer, Phys. Rev. 108, 1175 (1957).

18 M.L. Cohen, in Superconductivity, edited by R.D. Parks (Marcel Dekker, New York, 1969), vol. 1, p. 615.

19 H. Kawaji, H. Horie, S. Yamanaka, and M. Ishikawa, Phys. Rev. Lett. 74, 1427 (1995).

20 K. Tanigaki, T. Shimizu, K. M. Itoh, J. Teraoka, Y. Moritomo, S. Yamanaka, Nature Mater. 2, 653 (2003).

21 D. Connétable, V. Timoshevskii, B. Masenelli, J. Beille, J. Marcus, B. Barbara, A. M. Saitta, G. M. Rignanese, P. Melinon, S. Yamanaka, X. Blase, Phys. Rev. Lett. 91, 247001 (2003).

22 E. A. Ekimov, V. A. Sidorov, E. D. Bauer, N. N. Mel'nik, N. J. Curro, J. D. Thompson, S. M. Stishov, Nature 428, 542 (2004). 
23 Y. Takano, M. Nagao, I. Sakaguchi, M. Tachiki, T. Hatano, K. Kobayashi, H. Umezawa, H. Kawarada, Appl. Phys. Lett. 85, 2851 (2004).

24 E. Bustarret, J. Kačmarčik, C. Marcenat, E. Gheeraert, C. Cytermann, J. Marcus, T. Klein, Phys. Rev. Lett. 93, 237005 (2004).

25 E. Bustarret, phys. stat. sol. (a) 205, 997 (2008); E. Bustarret, P. Achatz, B. Sacépé, C. Chapelier, C. Marcenat, L. Ortéga, T. Klein, Phil. Trans. A366, 267 (2008).

26 Y. Takano, J. Phys. Condens. Matter 21, 253201 (2009).

27 A. Kawano, H. Ishiwata, S. Iriyama, R. Okada, T. Yamaguchi, Y. Takano, H. Kawarada, Phys. Rev. B 82, 085318 (2010).

28 L. Boeri, J. Kortus, and O. K. Andersen, Phys. Rev. Lett. 93, 237002 (2004

29 K.-W. Lee and W. E. Pickett, Phys. Rev. Lett. 93, 237003 (2004).

30 X. Blase, Ch. Adessi, and D. Connetable, Phys. Rev. Lett. 93, 237004 (2004).

31 H. J. Xiang, Z. Li, J. Yang, J. G. Hou, and Q. Zhu, Phys. Rev. B 70, 212504 (2004).

32 F. Giustino, J. R. Yates, I. Souza, M. L. Cohen, and S. G. Louie, Phys. Rev. Lett. 98, 047005 (2007).

33 K.-W. Lee and W. E. Pickett, Phys. Rev. B 73, 075105 (2006).

34 T. Shirakawa, S. Horiuchi, Y. Ohta, and H. Fukuyama, J. Phys. Soc. Jpn. 76, 014711 (2007).

35 Y. Ohta, New Diamond and Frontier Carbon Technology 17, 33 (2007).

36 L. Boeri, J. Kortus, O.K. Andersen, J. Phys. Chem. Sol. 67, 552 (2006).

37 W. L. McMillan, Phys. Rev. 167, 331 (1968).

38 Y. Ma, J.S. Tse, T. Cui, D.D. Klug, L. Zhang, Y. Xie, Y. Niu, G. Zou, Phys. Rev. B 72, 014306 (2005).

39 K. Winzer, D. Bogdanov, C. Wild, Physica C 432, 65 (2005).

40 T. Klein, P. Achatz, J. Kacmarcik, C. Marcenat, F. Gustafsson, J. Marcus, E. Bustarret, J. Pernot, F. Omnès, Bo E. Sernelius, C. Persson, A. Ferreira da Silva, C. Cytermann, Phys. Rev. B 75, 165313 (2007).

41 A. Grockowiak, T. Klein, H. Cercellier, F. Lévy-Bertrand, X. Blase, J. Kačmarčik, T. Kociniewski, F. Chiodi, D. Débarre, G. Prudon, C. Dubois, C. Marcenat, Phys. Rev. B 88, 064508 (2013).

42 M.S. Osofsky, R.J. Soulen, Jr, J.H. Claassen, G. Trotter, H. Kim, J.S. Horwitz, Phys. Rev. B 66020502 (2002).

43 R.J. Soulen, M.S. Osofsky, L.D. Cooley, Phys Rev. B 68, 094505 (2003).

44 A. Floris, G. Profeta, N.N. Lathiotakis, M. Lüders, M.A.L. Marques, C. Franchini, E.K. U. Gross, A. Continenza, S. Massilda, Phys. Rev. Lett. 94, 037004 (2005). 
45 G. Baskaran, Sci. Technol. Adv. Mater. 9, 044101 (2008) ; J. Supercond. Nov. Magn. 21, 45 (2008). 46 Y. Yanase, N. Yorozu, J. Phys. Soc. Jpn., 78, 034715 (2009).

47 J.J. Mareš, M. Nesládek, P. Hubík, D. Kindl, J. Kristofík, Diam. Rel. Mater. 16, 1 (2007).

48 J.J. Mareš, P. Hubík, J. Kristofík, M. Nesládek, Sci. Technol. Adv. Mater. 9, 044101 (2008).

49 W.E. Pickett, Physica C 468, 126 (2008).

50 J.E. Moussa, M.L. Cohen, Phys. Rev. B 77, 064518 (2008).

51 M. Calandra, N. Vast, F. Mauri, Phys. Rev. B 69, 224505 (2004).

52 M. Calandra, F. Mauri, Phys. Rev. Lett. 101, 016401 (2008).

53 M. Cardona, Solid State Commun. 133, 3 (2005).

54 J.E. Hirsch, Phys. Scr. 80, 035702 (2009).

55 E. Bustarret, C. Marcenat, P. Achatz, J. Kačmarčik, F. Lévy, A. Huxley, L. Ortéga, E. Bourgeois, X. Blase, D. Débarre, J. Boulmer, Nature (London) 444, 465 (2006).

56 Z.A. Ren, J. Kato, T. Muranaka, J. Akimitsu, M. Kriener, Y. Maeno, J. Phys. Soc. Jpn. 76 (2007) 103710.

57 M. Kriener, T. Muranaka, J. Kato, Z.A. Ren, J. Akimitsu, Y. Maeno, Sci. Tech. Adv. Mat. 9, 044205 (2008).

58 E. Bourgeois and X. Blase, Appl. Phys. Lett. 90, 142511 (2007).

59 E.R. Margine, X. Blase, Appl. Phys. Lett. 93, 19250 (2008).

60 J. Noffsinger, F. Giustino, S.G. Louie, M.L. Cohen, Phys. Rev. B 79, 104511 (2009).

61 M. Kriener, Y. Maeno, T. Oguchi, Z.A. Ren, J. Kato, T. Muranaka, J. Akimitsu, Phys. Rev. B 78, 024517 (2008).

62 T. Muranaka, Y. Kikuchi, T. Yoshizawa, N. Shirakawa, J. Akimitsu, Sci. Technol. Adv. Mater. 9, 044204(2008).

63 M. Kriener, T. Muranaka, J. Akimitsu, Y. Maeno, Physica C 470, S602 (2010).

64 X. Blase, E. Bustarret, C. Chapelier, T. Klein, C. Marcenat, Nat. Mater. 8, 375 (2009).

65 T. Herrmannsdörfer, V. Heera, O. Ignatchik, M. Uhlarz, A. Mücklich, M.

Posselt, H. Reuther, B. Schmidt, K.-H. Heinig, W. Skorupa, M. Voelskow, C. Wündisch, R. Skrotzki, M. Helm, J. Wosnitza, Phys. Rev. Lett. 102, 217003 (2009).

66 S. Lebègue, phys. stat. sol. Rapid Res. Lett. 3, 224 (2009). 
67 R. Skrotzki, T. Herrmannsdörfer, V. Heera, J. Fiedler, A. Mücklich, M. Helm, J. Wosnitza, J. Low Temp. Phys. 37, 877 (2011).

68 T. Herrmannsdörfer, R. Skrotzki, V. Heera, A. Mücklich, B. Schmidt, W. Skorupa,M. Voelskow, M. Helm, J. Wosnitza,Supercond. Sci. Technol. 23, 034007 (2010).

69 J. Fiedler, V. Heera, R. Skrotzki, T. Herrmannsdörfer, M. Voelskow, A. Mücklich, S. Facsko, H. Reuther, M. Perego, K.-H. Heinig, B. Schmidt, W. Skorupa, G. Gobsch, M. Helm, Phys. Rev. B 85, 134530 (2012).

70 R. Skrotzki, J. Fiedler, T. Herrmannsdörfer, V. Heera, M. Voelskow, A. Mücklich, B. Schmidt, W. Skorupa, G. Gobsch, M. Helm, Appl. Phys. Lett. 97, 192505 (2010).

71 V. Heera, J. Fiedler, R. Hübner, B. Schmidt, M. Voelskow, W. Skorupa, R. Strotzki, T.

Herrmannsdörfer, J. Wosnitza, M. Helm, New J. Phys. 15, 083022 (2013).

72 K. lakoubovskii, Physica C 469, 675 (2009).

73 Y. Matsushita, P.A. Wianecki, A.T. Sommer, T.H. Geballe, I.R. Fisher, Phys. Rev. B 74, 134512 (2006).

74 E. Bourgeois, E. Bustarret, P. Achatz, F. Omnès, X. Blase, Phys. Rev. B 74, 094509 (2006).

75 N. Dubrovinskaia, R. Wirth, J. Wosnitza, T. Papageorgiou, H.F. Braun, N. Miyajima, L. Dubrovinsky, Proc. Nat. Ac. Sci. 105, 11619 (2008).

76 Y.-G. Lu, S. Turner, J. Verbeeck, S. Janssens, P. Wagner, K. Haenen, G. van Tendeloo, Appl. Phys. Lett. 101, 041907 (2012).

77 F. Dahlem, P. Achatz, O.A. Williams, D. Araujo, E. Bustarret, H. Courtois, Phys. Rev. B 82, 033306 (2010).

78 G. Zhang, S. Turner, E.A. Ekimov, J. Vanacken, M. Timmermans, T. Samuely, V.A. Sidorov, S.M. Stishov, Y.-G. Lu, B. Deloof, B. Goderis, G. van Tendeloo, J. Van de Vondel, V. Moshchalkov, Adv. Mater. 26, 2034 (2014).

79 V.D. Blank, B.A. Kulnitskiy, I. A. Prerzhogin, S.A. Terentiev, S.A. Nosukhin, M.S. Kuznetsov, Mat.Res. Exp. 1, 035905 (2014).

80 F.J. Ribeiro, M.L. Cohen, Phys. Rev. B 69, 212507 (2004).

81 H. Werheit, U. Kuhlmann, J. Phys. Condens. Matter 23, 435501 (2011).

82 G. Zhang, J. Vanacken, J. Van de Vondel, W. Decelle, J. Fritzsche, V.V. Moshchalkov, B.L. Willems, S.D. Janssens, K. Haenen, P. Wagner, J. Appl. Phys. 108, 013904 (2010).

83 K. Hoummada, F. Dahlem, T. Kociniewski, J. Boulmer, C. Dubois, G. Prudon, E. Bustarret, H. Courtois, D. Débarre, D. Mangelinck, Appl. Phys. Lett. 101, 182602 (2012).

84 G. Kerrien, J. Boulmer, D. Débarre, D. Bouchier, A. Grouillet, D. Lenoble, Applied Surf. Sci. 186, 45 (2002). 
85 V. Heera, A. Mücklich, M. Posselt, M. Voelskow, C. Wündisch, B. Schmidt, R. Strotzki, K.H. Heinig, T. Herrmannsdörfer, W. Skorupa, J. Appl. Phys. 107, 053508 (2010).

86 A. Grockowiak, T. Klein, E. Bustarret, J. Kačmarčik, C. Dubois, G. Prudon, K. Hoummada, T. Kociniewski, D. Débarre, J. Boulmer, C. Marcenat, Supercond. Sci. \& Tech. 26, 042009 (2013).

87 T. H. Hsieh, H. Lin, J. Liu, W. Duan, A. Bansil, L. Fu, Nat. Comm. 3, 982 (2012).

88 Y. Tanaka, Z. Ren, T. Sato, K. Nakayama, S. Souma, T. Takahashi, K. Segawa, Y. Ando, Nat. Phys. 8, 800 (2012).

89 A. S. Erickson, J.-H. Chu, M. F. Toney, T. H. Geballe, I. R. Fisher, Phys. Rev. B 79, 024520 (2009).

90 I.A. Chernik, S.N. Lykov, Sov. Phys. Sol. State 23, 817 (1981).

91 Y. Matsushita, H. Bluhm, T.H. Geballe, I.R. Fisher, Phys. Rev. Lett. 94, 157002 (2005).

92 M. Novak, S. Sasaki, M. Kriener, K.Segawa, Y. Ando, Phys. Rev B 88, 140502 (2013).

93 R. Viennois, K. Niedziolka, P. Jund, Phys. Rev. B 88, 174302 (2013).

94 X. Lin, Z. Zhu, B. Fauqué, K. Behnia, Phys. Rev. X 3, 021002 (2013).

95 X. Lin, G. Bridoux, A. Gourgout, G. Seyfarth, S. Krämer, M. Nardone, B. Fauqué, K. Behnia, Phys. Rev. Lett. 112, 207002 (2014).

96 G. Binnig, A. Baratoff, H.E. Koenig, J.G. Bednorz, Phys. Rev. Lett. 45, 1352 (1980).

97 N. Reyren, S. Thiel, A.D. Caviglia, L. Fitting Kourkoutis, G. Hammerl, C. Richter, C.W. Schneider, T. Kopp, A.-S. Rüetschi, D. Jaccard, M. Gabay, D.A. Muller, J.-M. Triscone, J. Mannhart, Science 317, 1196 (2007).

98 J. Biscaras, N. Bergéal, A. Kushwaha, T. Wolf, A. Rastogi, R.C. Budhani, J. Lesueur, Nat. Comm. 1, 89 (2010).

99 K. Ueno, S. Nakamura, H. Shimotani, H.T. Yuan, N. Kimura, T. Nojima, H. Aoki, Y. Iwasa, M. Kawasaki, Nat. Nanotech. 6, 408 (2011).

100 R. Tsu, W.E. Howard, L. Esaki, Phys. Rev. 172, 779 (1968).

101 R. Fallica, F. Volpe, M. Longo, C. Wiemer, O. Salicio, A. Abrutis, Appl. Phys. Lett. 101, 102105 (2012).

102 V.A. Sidorov, E.A. Ekimov, S.M. Stishov, E.D. Bauer, J.D. Thompson, Phys. Rev. B 71, 060502 (2005). Erratum : Phys. Rev. B 74, 229903 (2006).

103 N. Dubrovinskaia, L. Dubrovinsky, T. Papageorgiou, A. Bosak, M. Krisch, H.F. Braun, J. Wosnitza, Appl. Phys. Lett. 92, 132506 (2008).

104 P.P. Edwards, M.J. Sienko, Phys. Rev. B 17, 2575 (1978).

105 P.P. Edwards, T.V. Ramakrishnan, C.N.R. Rao, J. Phys. Chem. 99, 5228 (1995). 
106 P. Dai, Y. Zhang, M.P. Sarachik, Phys. Rev. Lett. 66, 1914 (1991).

107 Y. Takada, J. Phys. Soc. Jpn 49, 1267 (1980).

108 A. Spinelli, M.A. Torija, C. Liu, C. Jan, C. Leighton, Phys. Rev. B 81, 155110 (2010).

109 K. Ishizaka, R. Eguchi, S. Tsuda, T. Yokoya, A. Chainani, T. Kiss, T. Shimojima, T. Togashi, S.

Watanabe, C.-T. Chen, C.Q. Zhang, Y. Takano, M. Nagao, I. Sakaguchi, T. Takenouchi, H. Kawarada, S. Shin, Phys. Rev. Lett. 98, 047003 (2007).

110 E. Ambler, J.H. Colwell, W.R. Hosler, J.F. Schooley, Phys. Rev. 148, 280 (1966).

111 T. Yokoya, T. Nakamura, T. Matsushita, T. Muro, Y. Takano, M. Nagao, T. Takenouchi, H. Kawarada, Nature 438, 647 (2005).

112 H. Okazaki, T. Yokoya, J. Nakamura, N. Yamada, T. Nakamura, T. Muro, Y. Tamenori, T. Matsushita, Y. Takata, T. Tokushima, S. Shin, Y. Takano, M. Nagao, T. Takenouchi, H. Kawarada, T. Oguchi, J. Phys. Chem. Sol. 69, 2978 (2008).

113 H. Guyot, P. Achatz, A. Nicolaou, P. Lefèvre, A. Taleb-Ibrahimi, E. Bustarret, submitted for publication.

114 A. Bhaduri, T. Kociniewski, F. Fossard, J. Boulmer, D. Débarre, Appl. Surf. Sci. 258, 9228 (2012).

115 E. Bustarret, F. Pruvost, M. Bernard, C. Cytermann, C. Uzan-Saguy, phys. stat. sol. (a) 186, 303 (2001).

116 M. Ortolani, S. Lupi, L. Baldassare, U. Schade, P. Calvani, Y. Takano, M. Nagao, T. Takenouchi, H. Kawarada, Phys. Rev. Lett. 97, 097002 (2006).

117 J. Bousquet, G. Chicot, D. Eon, E. Bustarret, Appl. Phys. Lett. 104, 021905 (2014).

118 K. Ishizaka, R. Eguchi, S. Tsuda, A. Chanaini, T. Yokoya, T. Kiss, T. Shimojima, T. Togashi, S. Watanabe, C.-T. Chen, Y. Takano, M. Nagao, I. Sakaguchi, T. Takenouchi, H. Kawarada, S. Shin, Phys. Rev. Lett. 100, 166402 (2008).

119 E.A. Ekimov, V.A. Sidorov, A.V. Rakhmanina, N.N. Mel'nik, R.A. Sadykov, J.D. Thompson, Sci. Tech. Adv. Mat. 7, S2 (2006).

120 E. Bustarret, E. Gheeraert, K. Watanabe, phys. stat. sol. (a) 199, 9 (2003). 
121 C. Marcenat, J. Kačmarčik, R. Piquerel, P. Achatz, G. Prudon, C. Dubois, B. Gautier, J.C. Dupuy, E. Bustarret, L. Ortega, T. Klein, J. Boulmer, T. Kociniewski, D. Débarre, Phys. Rev. B 81, 020501 (2010). 122 T. Wojewoda, P. Achatz, L. Ortéga, F. Omnès, C. Marcenat, E. Bourgeois, X. Blase, F. Jomard, E. Bustarret, Diam. Rel. Mater. 17, 1302 (2008).

123 B. Sacépé, C. Chapelier, C. Marcenat, J. Kačmarčik, T. Klein, F. Omnès, E. Bustarret, phys. stat. sol. (a) 203, 3315 (2006).

124 M. Hoesch, T. Fukuda, J. Mizuki, T. Takenouchi, H. Kawarada, J.P. Sutter, S. Tsutsui, A.Q.R. Baron, Phys. Rev. B 75, 140508 (2007).

125 M. Hoesch, J. Serrano, M. Krisch, P. Achatz, E. Bustarret, unpublished.

126 P.A. Lee, T.V. Ramakrishnan, Rev. Mod. Phys. 57, 287 (1985).

127 J.J. Mareš, P. Hubík, M. Nesládek, D. Kindl, J. Krištofik, Diam. Rel. Mat. 15, 1863 (2006).

128 P. Achatz, W. Gajewski, E. Bustarret, C. Marcenat, R. Piquerel, C. Chapelier, T. Dubouchet, O.A. Williams, K. Haenen, J.A. Garrido, M. Stutzmann, Phys. Rev. B 79, 201203 (2009).

129 G. Zhang, M. Zeleznik, J. Vanacken, P.W. May, V.V. Moshchalkov, Phys. Rev. Lett. 110, 077001 (2013).

130 B.L. Willems, G. Zhang, J. Vanacken, V.V. Moshchalkov, S.D. Janssens, O.A. Williams, K. HAenen, P. Wagner, J. Appl. Phys. 106, 033711 (2009).

131 J.J. Mareš, P. Hubík, M. Nesládek, J. Krištofik, Diam. Rel. Mat. 16, 921 (2007).

132 M. Dzero, J. Schmalian, Phys. Rev. Lett. 94, 157003 (2005).

133 Y. Kato, F. Matsui, T. Shimizu, H. Daimon, T. Matsushita, F.Z. Guo, T. Tsuno, Appl. Phys. Lett. 91, 251914 (2007).

134 M. Murakami, T. Shimizu, M. Tansho, Y. Takano, S. Ishii, E.Ekimov, V. Sidorov, H. Kawarada, K. Takegoshi, Jpn. J. Appl. Phys. 46, L1138 (2007).

135 S. Kitagoh, R. Okada, A. Kawano, M. Watanabe, Y. Takano, T. Yamaguchi, T. Chikyow, H. Kawarada, Physica C 470, S610 (2010).

136 M.P. Alegre, D. Araujo, A. Fiori, J.C. Piñero, F. Lloret, M.P. Villar, P. Achatz, G. Chicot, E. Bustarret, F. Jomard, Appl. Phys. Lett. 105, 173103 (2014).

137 F. Tomioka, S. Tsuda, T. Yamaguchi, H. Kawarada, Y. Takano, Physica C 468, 1228 (2008).

138 G. Binnig, H.E. Hoenig, Sol. St. Comm. 14, 597 (1974).

139 B. Sacépé, C. Chapelier, C. Marcenat, J. Kačmarčik, T. Klein, M. Bernard, E. Bustarret, Phys. Rev. Lett. 96, 097006 (2006). 
140 V.A. Sidorov, E.A. Ekimov, A.V. Rakhmanina, S.M. Stishov, N.N. Mel'nik, E.D. Bauer, J.D. Thompson, High Pr. Res. 26, 455 (2006).

141 T. Nishizaki, Y. Takano, M. Nagao, T. Takenouchi , H. Kawarada, N. Kobayashi, Sci. Tech. Adv. Mat. 7, S22 (2006)

142 T. Nishizaki, T. Sasaki, N. Kobayashi, Y. Takano, M. Nagao, H. Kawarada, Int. J. Mod. Phys. B 27, 1362014 (2013)

143 F. Dahlem, T. Kociniewski, C. Marcenat, A. Grockowiak, L.M.A. Pascal, P. Achatz, J. Boulmer, D. Débarre, T. Klein, E. Bustarret, H. Courtois, Phys. Rev. B 82, 140505 (2010).

144 E.A. Ekimov, V.A. Sidorov, A.V. Zoteev, Y.B. Lebed, J.D. Thompson, S.M. Stishov, Sci. Tech. Adv. Mat. 9, 044210 (2008).

145 P.Achatz, F. Omnès, L. Ortéga, C. Marcenat, J. Vacik, V. Hnatowicz, U. Köster, F. Jomard, E. Bustarret, Diam. Rel. Mat. 19, 814 (2010).

146 J.P. Carbotte, M. Greeson, A. Perez-Gonzalez, Phys. Rev. Lett. 66, 1789 (1991).

147 A.M. Finkel'stein, Physica B 197, 636 (1994).

148 M.P.A. Fisher, Phys. Rev. Lett. 65, 7 (1990).

149 J. Bousquet, PhD thesis, Université Grenoble Alpes, 2015.

150 D. G. Naugle, R.E. Glover, Phys. Lett. A 28, 611 (1969).

151 J. Simonin, Phys. Rev. B 33, 7830 (1986).

152 G. Zhang, S.D. Janssens, J. Vanacken, M. Timmermanns, J. Vacik, G.W. Ata klti, W. Decelle, W. Gililijns, B. Goderis, K. haenen, P. Wagner, V.V. Moshchalkov, Phys. Rev. B 84, 214517 (2011).

153 P. Achatz, E. Bustarret, C. Marcenat, R. Piquerel, T. Dubouchet, C. Chapelier, A.M. Bonnot, O.A. Williams, K. Haenen, W. Gajewski, J.A. Garrido, M. Stutzmann, phys. stat. sol. A 206, 1978 (2009).

154 W. Gajewski, P. Achatz, O.A. Williams, K. Haenen, E. Bustarret, M. Stutzmann, J.A. Garrido, Phys. Rev. B 79, 045206 (2009).

155 S.D. Janssens, P. Pobedinskas, J. Vacik, V. Petrakova, B. Ruttens, J. D'Haen, M. Nesladek, K. Haenen, P. Wagner, New J. Phys. 13, 083008 (2011).

156 S.Mandal, C. Naud, O.A. Wiliams, E. Bustarret, F. Omnès, P. Rodière, T. Meunier, L. Samidayar, C. Bäuerle, Nanotech. 21, 195303 (2010).

157 S. Mandal, T. Bautze, O.A. Williams, C. Naud, E. Bustarret, F. Omnès, P. Rodière, T. Meunier, C. Bäuerle, L. Saminadayar, ACS Nano 5, 7144 (2011).

158 T. Bautze, S. Mandal, O.A. Williams, P. Rodière, T. Meunier, C. Bäuerle, Carbon 72, 100 (2014).

159 M. Watanabe, A. Kawano, S. Kitagoh, T. Yamaguchi, Y. Takano, H. Kawarada, Physica C 470, S613 (2010). 
160 M. Watanabe, R. Kanomata, S. Kurihara, A. Kawano, S. Kitagoh, T. Yamaguchi, Y. Takano, H. Kawarada, Phys. Rev. B 85, 184516 (2012).

161 G. Chicot, A. Fiori, P.N. Volpe, T.N. Tran Thi, J.C. Gerbedoen, J. Bousquet, M.P. Alegre, J.C. Piñero, D. Araujo, F. Jomard, A. Soltani, J.C. De Jaeger, J. Morse, J. Härtwig, N. Tranchant, C. Mer-Calfati, J.C. Arnault, J. Delahaye, T. Grenet, D. Eon, F. Omnès, J. Pernot, E. Bustarret, J. Appl. Phys. 116, 083702 (2014).

162 Y.P.Shim, C.Tahan, Nat. Comm. 5, 4225 (2014).

163 K. Ueno, S. Nakamura, H. Shimotani, A. Ohtomo, N. Kimura, T. Nojima, H. Aoki, Y. Iwasa, M. Kawasaki, Nature Materials 7, 855 (2008).

164 N.T. Bagraev, L.E. Klyachkin, A.A. Koudryavstev, A.M. Malyarenko, V.V. Romanov, Semiconductors 43, 1441 (2009).

165 N.T. Bagraev, W. Gehlhoff, L.E. Klyachkin, A.M. Malyarenko, V.V. Romanov, S.A. Rykov, Physica C 437-8, 21 (2006).

166 E. Šimánek, Sol. St. Comm. 32, 731 (1979).

167 C.S. Ting, D.N. Talwar, K.L. Ngai, Phys. Rev. Lett. 45, 1213 (1980).

168 H. Okazaki, T. Wakita, T. Muro, T. Nakamura, Y. Muraoka, T. Yokoya, S.I. Kurihara, H. kawarada, T. Oguchi, Y. Takano, cond-mat ArXiv:1411.7752.

169 J.E. Moussa, M.L. Cohen, Phys. Rev. B 77, 064518 (2008).

170 W.E. Pickett, Physica C 468, 126 (2008). 
Tables

\begin{tabular}{|c|c|c|c|c|c|c|c|c|}
\hline & $\begin{array}{c}\text { Low T crystal } \\
\text { phase }\end{array}$ & $\mathrm{E}_{\mathrm{G}}(\mathrm{eV})$ & $\begin{array}{c}\theta_{\mathrm{D}} \\
(\mathrm{K})\end{array}$ & $\begin{array}{c}\varepsilon_{\mathrm{r}} \\
\left(/ \varepsilon_{0}\right)\end{array}$ & Dop. & $\begin{array}{c}\mathrm{r}_{\mathrm{Bohr}} \\
(\mathrm{nm})\end{array}$ & $\begin{array}{c}\mathrm{n}_{\mathrm{C}} \mathrm{min} \\
\left(\mathrm{nm}^{-3}\right)\end{array}$ & $\begin{array}{c}\mathrm{m}^{*} \mathrm{~T}_{\mathrm{F}} \mathrm{min} \\
(\mathrm{K})\end{array}$ \\
\hline $\mathrm{SnTe}$ & rocksalt & $0.19-0.3$ & 140 & 1200 & $\mathrm{~V}_{\mathrm{Sn}}$ & 230 & $0.25^{(98)}$ & 1680 \\
\hline $\mathrm{GeTe}$ & fcr distorted & $0.1-0.2$ & 170 & 36 & $\mathrm{~V}_{\mathrm{Ge}}$ & 2 & $0.9^{(98)}$ & 3950 \\
\hline $\mathrm{PbTe}$ & rocksalt & 0.35 & 140 & 1000 & $\mathrm{Tl}, \mathrm{In}$ & 250 & 0.05 & 570 \\
\hline $\begin{array}{c}\mathrm{SrTiO} \\
\mathrm{n}-\mathrm{type}\end{array}$ & $\begin{array}{c}\text { Tetragonal } \\
\text { (Perovskite) }\end{array}$ & 3.1 & 450 & 20000 & $\begin{array}{c}\mathrm{V}_{\mathrm{O}} \\
\mathrm{Nb}\end{array}$ & 600 & $0.0005^{(93)}$ & $24^{(93)}$ \\
\hline $\mathrm{Ge}$ & diamond & 0.66 & 360 & 16 & $\mathrm{Ga}$ & 5 & $0.2^{(67)}$ & 1450 \\
\hline $\mathrm{Si}$ & diamond & 1.1 & 640 & 12 & $\mathrm{~B}$ & 2 & $0.3^{(41)}$ & 1890 \\
\hline $3 \mathrm{C}-\mathrm{SiC}$ & Zincblende & 2.4 & 1270 & 9.7 & $\mathrm{~B}, \mathrm{Al}$ & 1 & $0.4^{(62)}$ & 2300 \\
\hline $6 \mathrm{H}-\mathrm{SiC}$ & hexagonal & 3 & 1200 & $9.6-10$ & $\mathrm{~B}$ & 1 & $0.25^{(57)}$ & 1680 \\
\hline $\mathrm{C}$ & diamond & 5.5 & 2000 & 5.7 & $\mathrm{~B}$ & 0.4 & $0.4^{(27)}$ & 2300 \\
\hline
\end{tabular}

Table 1: Normal state general properties of some superconducting semiconductors. The bandgap width $E_{G}$, the Debye temperature $\theta_{D}$ and the relative permittivity at low frequency $\varepsilon_{r}$ are those of the undoped material. The minimum carrier concentration for which superconductivity has been reported ( $n_{c}$ min) has been measured by Hall effect, except for silicon (italics). 


\begin{tabular}{|c|c|c|c|c|c|c|c|c|}
\hline & Dopant & $\begin{array}{c}\mathrm{n}_{\mathrm{H}} \\
\left(\mathrm{nm}^{-3}\right)\end{array}$ & $\begin{array}{c}\mathrm{k}_{\mathrm{F}} \\
\left(\mathrm{nm}^{-1}\right)\end{array}$ & $\begin{array}{c}\sigma_{4 \mathrm{~K}} \\
(\Omega \mathrm{cm})^{-1}\end{array}$ & RRR & $\begin{array}{c}\mathrm{L}_{m f p} \\
(\mathrm{~nm})\end{array}$ & $\mathrm{k}_{\mathrm{F}} \mathrm{L}_{\mathrm{mfp}}$ & reference \\
\hline $\mathrm{SnTe}$ & $\mathrm{V}_{\mathrm{Sn}}$ & 1 & 0.63 & $2.5 \times 10^{4}$ & - & 39 & 25 & Ref. 11 \\
\hline $\mathrm{SnTe}$ & $\mathrm{V}_{\mathrm{Sn}}$ & 2 & 0.78 & $2 \times 10^{4}$ & - & 17 & 13 & Ref. 11 \\
\hline $\mathrm{GeTe}$ & $\mathrm{V}_{\mathrm{Ge}}$ & 0.86 & 2.9 & $2 \times 10^{4}$ & - & 30 & 87 & Ref. 11 \\
\hline $\mathrm{GeTe}$ & $\mathrm{V}_{\mathrm{Ge}}$ & 0.18 & 1.7 & $1.3 \times 10^{4}$ & 1.3 & 40 & 68 & Ref. 100 \\
\hline $\mathrm{PbTe}$ & $\mathrm{Tl}$ & 0.05 & 1.1 & $3 \times 10^{3}$ & & 14 & 15 & Refs 73 \& 91 \\
\hline $\mathrm{PbTe}$ & $\mathrm{Tl}$ & 0.09 & 1.4 & $10^{3}$ & & 3.2 & 4.5 & Refs 73 \& 91 \\
\hline $\mathrm{SrTiO}_{3}$ & $\mathrm{~V}_{\mathrm{O}}$ & $5.5 \times 10^{-4}$ & 0.24 & $10^{3}$ & 2700 & 140 & 33 & Refs 94 \& 107 \\
\hline $\mathrm{SrTiO}_{3}$ & $\mathrm{~V}_{\mathrm{O}}$ & $4 \times 10^{-3}$ & 0.37 & $4 \times 10^{3}$ & 480 & 140 & 52 & Refs 94 \& 107 \\
\hline $\mathrm{SrTiO}_{3}$ & $\mathrm{~V}_{\mathrm{O}}$ & 0.027 & 0.51 & $1.510^{4}$ & 490 & 120 & 61 & Refs 94 \& 107 \\
\hline $\mathrm{SrTiO}_{3}$ & $\mathrm{Nb}$ & 0.16 & 0.56 & $10^{5}$ & 120 & 37 & 21 & Refs 94 \& 107 \\
\hline $\mathrm{Ge}$ & $\mathrm{Ga}$ & 0.53 & 2.5 & $5 \times 10^{3}$ & 1 & 7 & 18 & Ref. 67 \\
\hline $\mathrm{Si}$ & $\mathrm{B}$ & 5 & 5.3 & $8 \times 10^{3}$ & 1.25 & 1.3 & 6.9 & Ref. 55 \\
\hline $\mathrm{Si}$ & $\mathrm{B}$ & 0.55 & 2.5 & $8 \times 10^{3}$ & 1.2 & 3.2 & 8.1 & Ref. 41 \\
\hline $\mathrm{Si}$ & $\mathrm{B}$ & 1.4 & 3.5 & $1.6 \times 10^{4}$ & 1.2 & 3.4 & 12 & Ref. 41 \\
\hline $\mathrm{Si}$ & $\mathrm{B}$ & 2.8 & 4.4 & $1.4 \times 10^{4}$ & 1.3 & 2 & 8.7 & Ref. 41 \\
\hline $3 \mathrm{C}-\mathrm{SiC}$ & $\mathrm{B}$ & 1.9 & 3.8 & $1.6 \times 10^{4}$ & 11 & 14 & 53 & Ref. 62 \\
\hline $3 \mathrm{C}-\mathrm{SiC}$ & $\mathrm{Al}$ & 0.7 & 2.8 & $1.3 \times 10^{3}$ & 5.3 & 2.2 & 6.2 & Ref. 62 \\
\hline $6 \mathrm{H}-\mathrm{SiC}$ & $\mathrm{B}$ & 0.25 & 2.3 & $8 \times 10^{2}$ & 4.7 & 3 & 6.9 & Ref. 62 \\
\hline $\mathrm{C}$ & $\mathrm{B}$ & 1.8 & 3.8 & $4 \times 10^{2}$ & 0.9 & 0.34 & 1.3 & Ref. 101 \\
\hline $\mathrm{C}_{(100)}$ & $\mathrm{B}$ & 0.56 & 2.6 & 70 & 2 & 0.23 & 0.5 & Ref. 39 \\
\hline $\mathrm{C}_{(100)}$ & $\mathrm{B}$ & 1.3 & 3.3 & $4 \times 10^{2}$ & 1.2 & 0.5 & 1.8 & Ref. 39 \\
\hline $\mathrm{C}_{(111)}$ & $\mathrm{B}$ & 2.1 & 4 & $5 \times 10^{2}$ & - & 0.6 & 2.4 & Ref. 108 \\
\hline $\mathrm{C}_{(111)}$ & $\mathrm{B}$ & 13 & 7.3 & $1.4 \times 10^{3}$ & 0.9 & 0.5 & 3.8 & Ref. 108 \\
\hline & & & & & & & & \\
\hline
\end{tabular}

Table 2: Normal state properties of some superconducting semiconductors for various doping-induced free carrier concentrations $n_{H}$ deduced from the Hall coefficient, except in the case of silicon where boron concentrations (in italics) have been used. The residual resistivity ratio RRR was defined as $\rho_{300 K} / \rho_{4 k}=\sigma_{4 k} / \sigma_{300 k}$. The mean free path $L_{m f p}$ was generally deduced from Hall mobility values within the free electron picture, and yielded the loffe-Regel parameter $k_{F} \mathrm{~L}_{m f p}$. 


\begin{tabular}{|c|c|c|c|c|c|c|c|c|}
\hline & $\begin{array}{c}\mathrm{n}_{\mathrm{H}} \\
\left(\mathrm{nm}^{-3}\right)\end{array}$ & $\begin{array}{l}\mathrm{T}_{\mathrm{C}} \\
(\mathrm{K})\end{array}$ & $\begin{array}{c}\mathrm{H}_{\mathrm{C} 2}(0) \text { or } \\
\mathrm{H}_{\mathrm{C}} \text { (Tesla) }\end{array}$ & $\begin{array}{c}\xi_{0} \\
(\mathrm{~nm})\end{array}$ & $\begin{array}{l}\xi_{\mathrm{GL}} \\
(\mathrm{nm})\end{array}$ & $\begin{array}{c}\lambda_{\mathrm{L}} \\
(\mathrm{nm})\end{array}$ & $\begin{array}{c}\kappa_{\mathrm{GL}} \\
(\mathrm{nm})\end{array}$ & type \\
\hline $\mathrm{Sn}_{1-\delta} \mathrm{Te}$ & 1 & 0.065 & $5 \times 10^{-4}$ & 6200 & 490 & 55 & 1.4 & II, dirty ${ }^{11}$ \\
\hline $\mathrm{Sn}_{1-\delta} \mathrm{Te}$ & 2 & 0.21 & $8.5 \times 10^{-4}$ & 2400 & 230 & 63 & 3.7 & II, dirty ${ }^{11}$ \\
\hline $\mathrm{Ge}_{1-\delta} \mathrm{Te}$ & 0.86 & 0.08 & $1.6 \times 10^{-3}$ & 3900 & 340 & 75 & 2.5 & II, dirty ${ }^{11}$ \\
\hline $\mathrm{Ge}_{1-\delta} \mathrm{Te}$ & 1.5 & 0.31 & 0.038 & 1200 & 140 & 110 & 6.8 & II, dirty ${ }^{11}$ \\
\hline PbTe:Tl & 0.09 & 1.15 & 0.39 & 260 & 29 & 160 & 5 & II, dirty ${ }^{73}$ \\
\hline PbTe:TI & 0.11 & 1.4 & 0.6 & 300 & 24 & 150 & 8 & II, dirty ${ }^{73}$ \\
\hline $\mathrm{SrTiO}_{3-\delta}$ & $5.5 \times 10^{-4}$ & 0.09 & 0.05 & & 100 & 5800 & & II, clean ${ }^{94}$ \\
\hline $\mathrm{SrTiO}_{3-\delta}$ & $4 \times 10^{-3}$ & 0.18 & 0.11 & & 56 & 2200 & & II, clean ${ }^{94}$ \\
\hline $\mathrm{SrTiO}_{3-\delta}$ & 0.032 & 0.34 & 0.15 & & 44 & 760 & & II, clean ${ }^{94}$ \\
\hline $\mathrm{SrTiO}_{3}: \mathrm{Nb}$ & 0.16 & 0.43 & 0.22 & & 37 & 340 & & II, clean ${ }^{94}$ \\
\hline Ge:Ga & 0.53 & 0.5 & 0.5 & 100 & 26 & $>100$ & $>14$ & II, dirty ${ }^{67}$ \\
\hline Si:B & 4 & 0.58 & 0.11 & 1000 & 50 & 60 & 20 & II, dirty ${ }^{118}$ \\
\hline 3C-SiC:B & 1.9 & 1.5 & 0.013 & 360 & 70 & 130 & 0.32 & I, dirty ${ }^{62}$ \\
\hline 3C-SiC:Al & 0.7 & 1.5 & 0.037 & 150 & 18 & 210 & 1.8 & II, dirty ${ }^{62}$ \\
\hline 6H-SiC:B & 0.25 & 1.4 & 0.012 & 200 & 24 & 360 & 0.31 & I, dirty ${ }^{62}$ \\
\hline$C: B$ & 1.8 & 4.5 & 4.2 & 240 & 9 & 160 & 18 & II, dirty ${ }^{99}$ \\
\hline$C_{(100)}: B$ & 1.3 & 0.38 & 0.37 & - & 30 & 225 & 7.6 & II, dirty ${ }^{39}$ \\
\hline$C_{(100)}: B$ & 2.1 & 2.5 & 2.44 & 120 & 12 & 154 & 13 & II, dirty ${ }^{39}$ \\
\hline$C_{(111)}: B$ & 6 & 8 & 7 & 95 & 6.9 & 72 & 10 & II, dirty ${ }^{113}$ \\
\hline
\end{tabular}

Table 3 : Carrier density-dependent superconductivity parameters for various degenerate semiconductors: critical temperatures $T_{c}$ and magnetic fields $H_{c}$ (clean limit)or $H_{C 2}(T=0)$, coherence lengths $\xi_{0}$ and $\xi_{G L}$, London penetration length $\lambda_{L}$ and Ginzburg-Landau coefficient $\kappa_{G L}$, as well the type of superconductivity. 


\section{Figure captions :}

Figure 1 : Nominal free carrier dependence of the critical temperature $T_{c}$ for the superconductive transition of various heavily doped degenerate semiconductors : B-doped diamond grown along 27,39 (100) or $^{27}$ (111), B-doped silicon for two different epitaxial film thicknesses ${ }^{41}$, Ga-doped germanium ${ }^{67-}$ ${ }^{69}, \mathrm{~B}$-doped ${ }^{62}$ or Al-doped ${ }^{57}$ silicon carbide, self-doped or $\mathrm{Nb}$-doped strontium titanate ${ }^{15,94}$, $\mathrm{Tl}$-doped lead telluride ${ }^{73}$, self-doped selenium ${ }^{8,9}$ and germanium ${ }^{5}$ tellurides. The lines correspond to $T_{c}$ estimates for three $\mu^{*}$ values, as deduced from equation 1 for $\theta_{D}=640 \mathrm{~K}$, $\lambda$ being evaluated by ab-initio supercell calculations ${ }^{41}$.

Figure 2 : Color-coded intensity (bottom) and spectral shift (top) maps onto the $X-\Gamma-K$ principal plane of the Brillouin zone of a boron doped diamond homoepitaxial layer(C:B), deduced respectively from (bottom) polarized Angle Resolved Photoemission Spectroscopy ${ }^{113}$ (ARPES) and from (top) Inelastic Xray Spectroscopy ${ }^{125}$ (IXS) measurements performed at SOLEIL (ARPES) and ESRF (IXS) synchrotron facilities. Different ARPES configurations allow to distinguish the contributions of the heavy hole (hh) and light hole (Ih) subbands. The spectral shift measured by IXS is that of the optical phonons of C:B with respect to those of the undoped crystal.

Figure 3 : Experimentally determined critical temperatures $T_{C}$ (either local or macroscopic) as a function of the pair binding energy(half-gap) $\Delta$ measured by tunnel spectroscopy at very low temperatures for diamond ${ }^{139-141}$, silicon ${ }^{143}$, germanium telluride ${ }^{16}$ and strontium titanate ${ }^{97,138}$. The straight line corresponds to the weak coupling BCS ratio. 
Figure 1

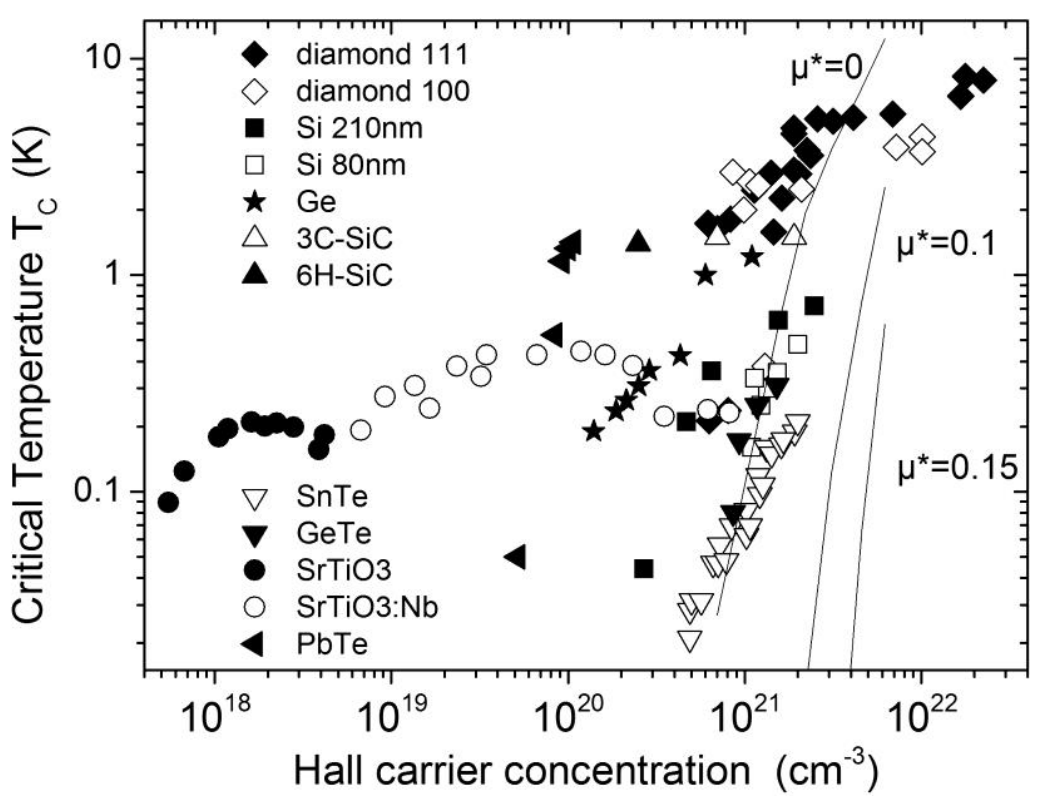

Figure 2

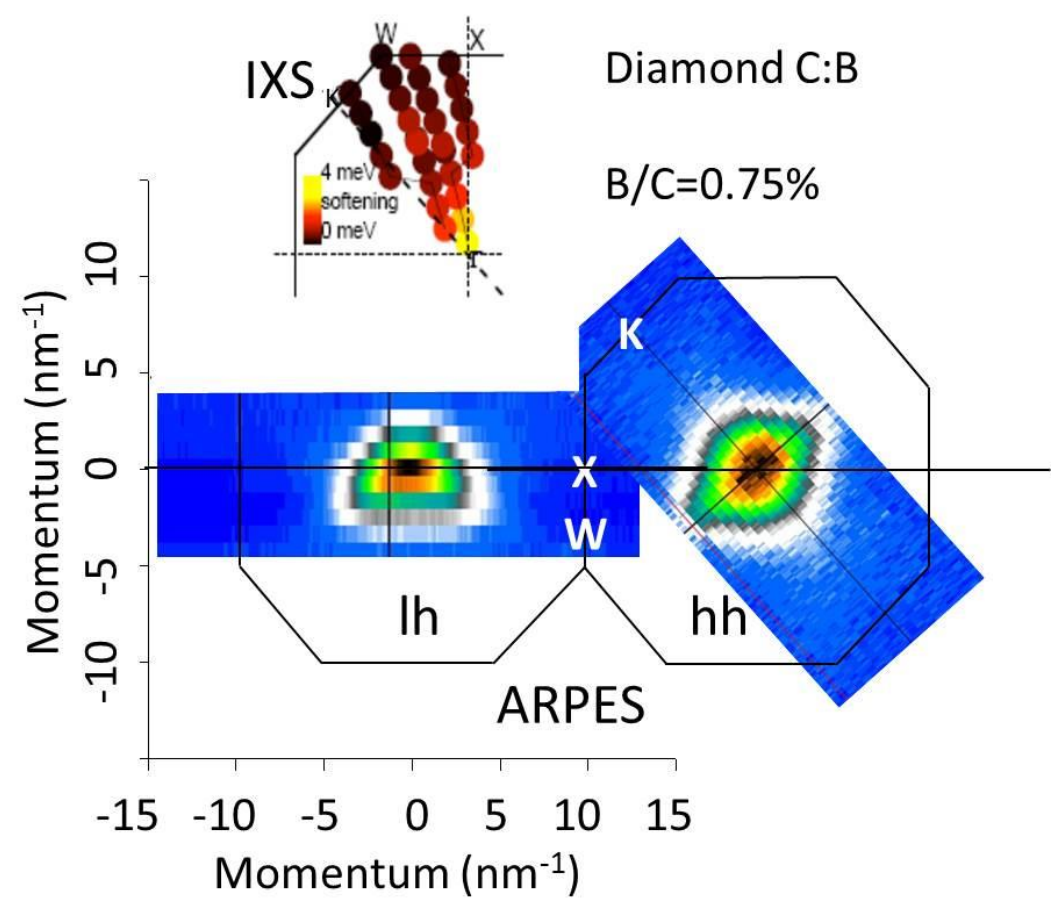


Figure 3

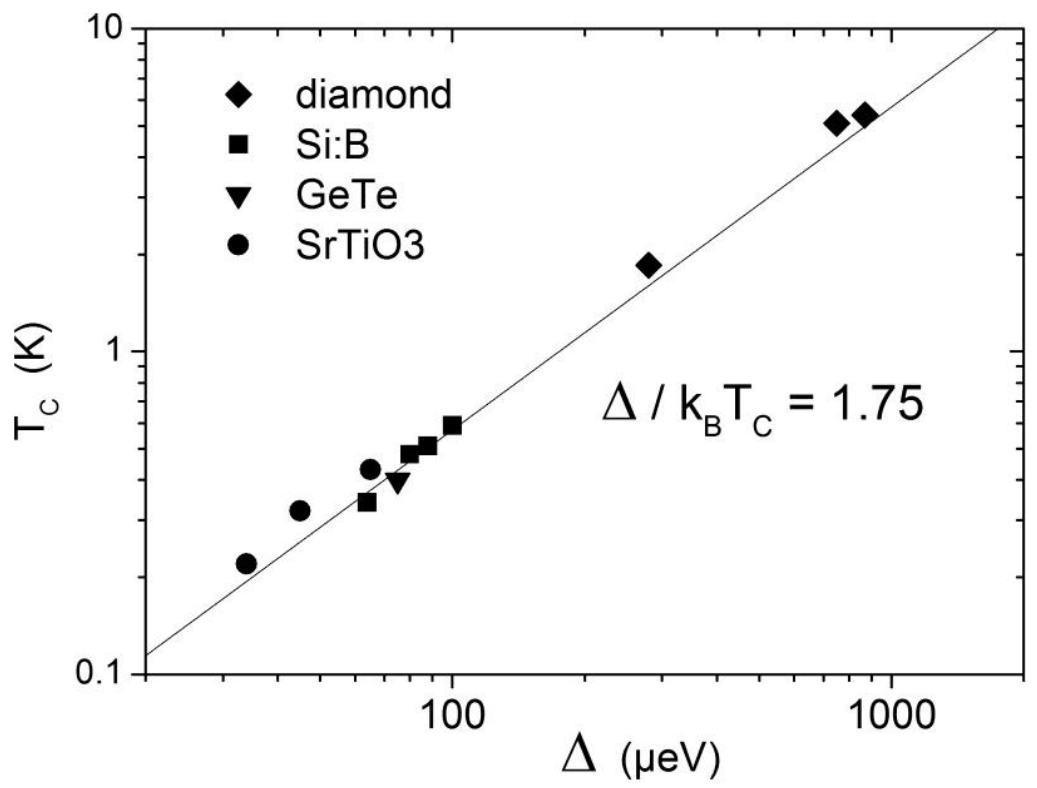

